DOI: https://doi.org/10.24297/jam.v20i.9076

\title{
Metallic Ratios and 3, 6, 9, The Special Significance of Numbers 3, 6, 9 in the Realm of Metallic Means
}

\author{
Dr. Chetansing Rajput \\ M.B.B.S. Nair Hospital (Mumbai University) India, \\ Asst. Commissioner (Govt. of Maharashtra) \\ Email: chetansingkrajput@gmail.com \\ Website: https://goldenratiorajput.com/
}

\author{
Lecture Link 1 : https://youtu.be/vBfVDaFnA2k \\ Lecture Link 2 : https://youtu.be/74uF4sBqYjs \\ Lecture Link 3 : https://youtu.be/raosniXwRhw \\ Lecture Link 4 : https://youtu.be/Qh2B1tMl8Bk
}

\begin{abstract}
This work illustrates the intriguing relation between Metallic Means and the Numbers 3,6 and 9. These numbers occupy special positions in the realm of Metallic Ratios, as elaborated herein.

Keywords: Metallic Mean, Pythagoras Theorem, Fibonacci, Pell, Lucas, Pi, Phi, Silver Ratio, Right Triangle, Metallic Numbers, Metallic Ratio Triads, 36 9, Pythagorean Triples, Bronze Ratio, Golden Ratio, Pascal's Triangle, Metallic Ratio

\section{Introduction}

The proponents of Vortex Based Mathematics will continue to make irrational claims, and their opponents will continue to debunk them on grounds of the Base-10 Number System. Let the both camps do their jobs with missionary zeal. Author's objective is just to appreciate the beauty of numbers and the special attributes of the numbers 3, 6 and 9, especially their unique patterns in the realm of Metallic Means.
\end{abstract}

Such intriguing pattern of the integers 3, 6 and 9 was introduced in the work mentioned in Reference [1].

The prime objective of this paper is to supplement that work and further illustrate the unique pattern of numbers 3, 6 and 9 in the domain of Metallic Numbers.

As a brief introduction, each Metallic Mean $\boldsymbol{\delta}_{\mathbf{n}}$ is the root of the simple Quadratic Equation $\mathbf{X}^{\mathbf{2}}-\mathbf{n} \mathbf{X}-\mathbf{1}=\mathbf{0}$, where $\mathbf{n}$ is any positive natural number.

Thus, the fractional expression of the $\mathrm{n}^{\text {th }}$ Metallic Ratio is $\boldsymbol{\delta}_{\mathbf{n}}=\frac{\mathbf{n}+\sqrt{\mathbf{n}^{2}+\mathbf{4}}}{\mathbf{2}}$

Moreover, each Metallic Ratio can be expressed as the continued fraction:

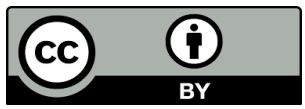


$\boldsymbol{\delta}_{\mathbf{n}}=\mathbf{n}+\frac{\mathbf{1}}{\mathbf{n}+\frac{\mathbf{1}}{\mathbf{n}+\frac{\mathbf{1}}{\mathbf{n}+\ldots}}} ;$ And hence, $\boldsymbol{\delta}_{\mathbf{n}}=\mathbf{n}+\frac{\mathbf{1}}{\boldsymbol{\delta} \mathbf{n}}$

......References: [3] [4] [5]

\section{Metallic Ratios and Numbers 3, 6 , 9}

Consider the Integer Sequences and the corresponding Lucas Sequences associated with various Metallic Means [13] [14]. Remarkably, the Digital Roots of every Fourth Terms of Fibonacci, Lucas, Pell and Pell-Lucas sequences are 3, 6 or 9. $\mathrm{F}_{4}, \mathrm{~F}_{8}, \mathrm{~F}_{12} \ldots \ldots . ., \mathrm{L}_{2}, \mathrm{~L}_{6}, \mathrm{~L}_{10} \ldots \ldots . ., \mathrm{P}_{4}, \mathrm{P}_{8}, \mathrm{P}_{12} \ldots \ldots . .$. and $\mathrm{PL}_{2}, \mathrm{PL}_{6}, \mathrm{PL}_{10} \ldots \ldots$ all have their Digital Roots 3,6 or 9 , and it holds true for the Integer Sequences as well as corresponding Lucas Sequences associated with any $\mathrm{n}^{\text {th }}$ Metallic Mean $\boldsymbol{\delta}_{\mathrm{n}}$; provided $\mathrm{n}$ is not multiple of 3 .

If $\mathrm{n}$ is multiple of 3, like Bronze Ratio $\boldsymbol{\delta}_{3}$ or the Aluminium Ratio $\boldsymbol{\delta}_{6}$ or the Ninth Mean $\boldsymbol{\delta}_{9}$ and so on : here, the digital roots of Alternate terms of associated Integer Sequences and corresponding Lucas Sequences are 3, 6, or 9.

\section{Mathematical Relations between different Metallic Means: The TRIADS of Metallic Ratios, and the Numbers 3, 6,9}

If $\mathbf{K}, \mathbf{m}$ and $\mathbf{n}$ are three positive integers such that $\mathbf{n}$ is the smallest of the three integers and $\frac{\mathbf{m n}+\mathbf{4}}{\mathbf{m}-\mathbf{n}}=\mathbf{k}$

then, it is observed that

$\frac{\boldsymbol{\delta}_{\mathrm{m}} \times \boldsymbol{\delta}_{\mathrm{n}}+\mathbf{1}}{\boldsymbol{\delta}_{\mathrm{m}}-\boldsymbol{\delta}_{\mathrm{n}}}=\boldsymbol{\delta}_{\mathrm{k}}$ where $\boldsymbol{\delta}_{\mathrm{k}}, \boldsymbol{\delta}_{\mathrm{m}}$ and $\boldsymbol{\delta}_{\mathrm{n}}$ are the $\mathrm{k}^{\text {th }}, \mathrm{m}^{\text {th }}$ and $\mathrm{n}^{\text {th }}$ Metallic Means respectively.

This explicit formula, among several other formulae those give the precise mathematical relations between different Metallic Means, has been recently published in the works mentioned in References [2] and [1].

The abovementioned explicit formula gives the "Triads" of Metallic Means, as $\left[\boldsymbol{\delta}_{\mathrm{n}}, \boldsymbol{\delta}_{\mathrm{m}}, \boldsymbol{\delta}_{\mathrm{k}}\right]$

Where $\frac{\mathrm{mn}+4}{\mathrm{~m}-\mathrm{n}}=\mathbf{k}$ and $\frac{\mathrm{kn}+4}{\mathrm{k}-\mathrm{n}}=\mathbf{m}$

hence, $\frac{\boldsymbol{\delta}_{\mathrm{m}} \times \boldsymbol{\delta}_{\mathrm{n}}+\mathbf{1}}{\boldsymbol{\delta}_{\mathrm{m}}-\boldsymbol{\delta}_{\mathrm{n}}}=\boldsymbol{\delta}_{\mathrm{k}}$ and also $\frac{\boldsymbol{\delta}_{\mathrm{k}} \times \boldsymbol{\delta}_{\mathrm{n}}+\mathbf{1}}{\boldsymbol{\delta}_{\mathrm{k}}-\boldsymbol{\delta}_{\mathrm{n}}}=\boldsymbol{\delta}_{\mathrm{m}}$

Moreover,

$$
\frac{\mathbf{k m}-\mathbf{4}}{\mathbf{k}+\mathbf{m}}=\mathbf{n} \quad \text { and } \quad \frac{\boldsymbol{\delta}_{\mathrm{k}} \times \boldsymbol{\delta}_{\mathrm{m}}-\mathbf{1}}{\boldsymbol{\delta}_{\mathrm{k}}+\boldsymbol{\delta}_{\mathrm{m}}}=\boldsymbol{\delta}_{\mathbf{n}}
$$


For example, if $n=6$, the three integers 6,11 and 14 satisfy the prerequisite $\frac{\mathbf{m n}+\mathbf{4}}{\mathbf{m}-\mathbf{n}}=\mathbf{k}$; Hence, the three Metallic means $\boldsymbol{\delta}_{6}, \boldsymbol{\delta}_{11}$ and $\boldsymbol{\delta}_{14}$ form a Triad $\left[\boldsymbol{\delta}_{6}, \boldsymbol{\delta}_{11}, \boldsymbol{\delta}_{14}\right]$ such that :

$$
\frac{\boldsymbol{\delta}_{11} \times \boldsymbol{\delta}_{6}+\mathbf{1}}{\boldsymbol{\delta}_{11}-\boldsymbol{\delta}_{6}}=\boldsymbol{\delta}_{14} \quad \text { and also } \quad \frac{\boldsymbol{\delta}_{14} \times \boldsymbol{\delta}_{6}+\mathbf{1}}{\boldsymbol{\delta}_{14}-\boldsymbol{\delta}_{6}}=\boldsymbol{\delta}_{11} \quad \text { Also, } \frac{\boldsymbol{\delta}_{14} \times \boldsymbol{\delta}_{11}-\mathbf{1}}{\boldsymbol{\delta}_{14}+\boldsymbol{\delta}_{11}}=\boldsymbol{\delta}_{\mathbf{6}}
$$

Noticeably, $\mathbf{n = 6}$ forms such multiple triads:

\begin{tabular}{|c|l|l|l|l|l|l|l|l|}
\hline $\mathrm{n}$ & 6 & 6 & 6 & 6 & 6 & 6 & 6 & 6 \\
\hline $\mathrm{m}$ & 7 & 8 & 10 & 11 & 14 & 16 & 26 & 46 \\
\hline $\mathrm{k}$ & 46 & 26 & 16 & 14 & 11 & 10 & 8 & 7 \\
\hline
\end{tabular}

: Shaded Triads have been exemplified above.

And, just like $\mathrm{n}=6$ exemplified above, every integer forms such multiple triads. Noticeably, every $\mathrm{n}^{\text {th }}$ Metallic Mean can give precise values of various Metallic Means by the formula: $\frac{\boldsymbol{\delta}_{m} \times \boldsymbol{\delta}_{n}+\mathbf{1}}{\boldsymbol{\delta}_{m}-\boldsymbol{\delta}_{n}}=\boldsymbol{\delta}_{k}$, maximum upto $\left(n^{2}+n+4\right)^{\text {th }}$ Metallic Mean: $\mathbf{m}_{\max }=\mathbf{k}_{\max }=\left(n^{2}+n+4\right)$

\section{Special Pattern regarding Numbers 3, 6 and 9 :}

Consider the TRIADS of Metallic Ratios with various integer values of $n$, as shown below in Table 1.

Noticeably, in the following Table 1 :

If $\mathrm{n}$ is NOT multiple of 3 , the alternate values of $\mathbf{m}$ and $\mathbf{k}$ have their digital roots 3,6 , or 9 .

And, if $n$ is multiple of $3:$ None of the associated $m_{s}$ and $k_{s}$ have their digital roots 3,6 , or 9 .

Table 1: "Triads" of Metallic Means formed by the First Ten Metallic Means:

\begin{tabular}{|c|c|c|c|c|c|c|c|c|}
\hline $\mathrm{n}$ & 1 & 1 & 1 & 1 & 1 & 1 & 1 & 1 \\
\hline $\mathrm{m}$ & 2 & 6 & & & & & & \\
\hline $\mathrm{k}$ & 6 & 2 & & & & & & \\
\hline
\end{tabular}




\begin{tabular}{|l|l|l|l|l|l|l|l|l|}
\hline$n$ & 2 & 2 & 2 & 2 & 2 & 2 & 2 & 2 \\
\hline$m$ & 3 & 4 & 6 & 10 & & & & \\
\hline$k$ & 10 & 6 & 4 & 3 & & & & \\
\hline
\end{tabular}

: Alternate $m_{s}$ and $k_{s}$ have their digital roots 3,6 , or 9 .

\begin{tabular}{|l|l|l|l|l|l|l|l|l|}
\hline $\mathbf{n}$ & 3 & 3 & 3 & 3 & 3 & 3 & 3 & 3 \\
\hline $\mathrm{m}$ & $\mathbf{4}$ & $\mathbf{1 6}$ & & & & & & \\
\hline $\mathrm{k}$ & 16 & $\mathbf{4}$ & & & & & & \\
\hline
\end{tabular}

\section{For $n=3,6,9$ :}

None of the associated $m_{s}$ and $k_{s}$ have their digital roots 3,6 , or 9 .

\begin{tabular}{|l|l|l|l|l|l|l|l|l|}
\hline $\mathrm{n}$ & 4 & 4 & 4 & 4 & 4 & 4 & 4 & 4 \\
\hline $\mathrm{m}$ & 5 & 6 & 8 & 9 & 14 & 24 & & \\
\hline $\mathrm{k}$ & 24 & 14 & 9 & 8 & 6 & 5 & & \\
\hline
\end{tabular}

\begin{tabular}{|l|l|l|l|l|l|l|l|l|}
\hline $\mathrm{n}$ & 5 & 5 & 5 & 5 & 5 & 5 & 5 & 5 \\
\hline $\mathrm{m}$ & 6 & 34 & & & & & & \\
\hline $\mathrm{k}$ & 34 & 6 & & & & & & \\
\hline
\end{tabular}

\begin{tabular}{|l|l|l|l|l|l|l|l|l|}
\hline $\mathrm{n}$ & 6 & 6 & 6 & 6 & 6 & 6 & 6 & 6 \\
\hline $\mathrm{m}$ & 7 & 8 & 10 & 11 & 14 & 16 & 26 & 46 \\
\hline $\mathrm{k}$ & 46 & 26 & 16 & 14 & 11 & 10 & 8 & 7 \\
\hline
\end{tabular}

: None of the associated $m_{s}$ and $k_{s}$ have their digital roots 3, 6, or 9 .

\begin{tabular}{|l|l|l|l|l|l|l|l|l|}
\hline $\mathbf{n}$ & 7 & 7 & 7 & 7 & 7 & 7 & 7 & 7 \\
\hline $\mathrm{m}$ & 8 & 60 & & & & & & \\
\hline $\mathrm{k}$ & 60 & 8 & & & & & & \\
\hline
\end{tabular}




\begin{tabular}{|l|l|l|l|l|l|l|l|l|}
\hline $\mathrm{n}$ & 8 & 8 & 8 & 8 & 8 & 8 & 8 & 8 \\
\hline $\mathrm{m}$ & 9 & 10 & 12 & 25 & 42 & 76 & & \\
\hline $\mathrm{k}$ & 76 & 42 & 25 & 12 & 10 & 9 & & \\
\hline
\end{tabular}

\begin{tabular}{|l|l|l|l|l|l|l|l|l|}
\hline $\mathrm{n}$ & 9 & 9 & 9 & 9 & 9 & 9 & 9 & 9 \\
\hline $\mathrm{m}$ & 10 & 14 & 26 & 94 & & & & \\
\hline k & 94 & 26 & 14 & 10 & & & & \\
\hline
\end{tabular}

: None of the associated $m_{s}$ and $k_{s}$ have their digital roots 3,6 , or 9 .

\begin{tabular}{|l|l|l|l|l|l|l|l|l|}
\hline $\mathrm{n}$ & 10 & 10 & 10 & 10 & 10 & 10 & 10 & 10 \\
\hline $\mathrm{m}$ & 11 & 12 & 14 & 18 & 23 & 36 & 62 & 114 \\
\hline $\mathrm{k}$ & 114 & 62 & 36 & 23 & 18 & 14 & 12 & 11 \\
\hline
\end{tabular}

More remarkably, the number of Triads formed ( or the numbers of $m_{s}$ and $k_{s}$ ) increase noticeably for $n=6$ and 9

For Even $\mathrm{n}_{\mathrm{s}}$ : the number of Triads exhibit noticeable rise at $\mathrm{n}=6,16,26 \ldots \ldots$ and so on.

For Odd $n_{s}$ : the number of Triads exhibit noticeable rise at $n=9,19,29 \ldots \ldots .$. and so on.

Moreover, it can be noticed from above Table : if $\mathbf{n}$ is multiple of 3, the Digital Root of $|\mathbf{k}-\mathbf{m}|$ is $\mathbf{3}, \mathbf{6}$ or $\mathbf{9}$.

And, if $\mathrm{n}$ is NOT multiple of 3 , the Digital Root of NONE of the $|\mathrm{k}-\mathrm{m}|$ value is 3,6 or 9 .

\begin{tabular}{|l|l|l|l|l|l|l|l|l|}
\hline $\mathrm{n}$ & 3 & 3 & 3 & 3 & 3 & 3 & 3 & 3 \\
\hline $\mathrm{m}$ & 4 & 16 & & & & & & \\
\hline $\mathrm{k}$ & 16 & 4 & & & & & & \\
\hline$|\mathrm{k}-\mathrm{m}|$ & 12 & 12 & & & & & & \\
\hline
\end{tabular}




\begin{tabular}{|l|l|l|l|l|l|l|l|l|}
\hline $\mathrm{n}$ & 6 & 6 & 6 & 6 & 6 & 6 & 6 & 6 \\
\hline $\mathrm{m}$ & 7 & 8 & 10 & 11 & 14 & 16 & 26 & 46 \\
\hline $\mathrm{k}$ & 46 & 26 & 16 & 14 & 11 & 10 & 8 & 7 \\
\hline$|\mathrm{k}-\mathrm{m}|$ & 39 & 18 & 6 & 3 & 3 & 6 & 18 & 39 \\
\hline
\end{tabular}

\begin{tabular}{|l|l|l|l|l|l|l|l|l|}
\hline $\mathrm{n}$ & 9 & 9 & 9 & 9 & 9 & 9 & 9 & 9 \\
\hline $\mathrm{m}$ & 10 & 14 & 26 & 94 & & & & \\
\hline $\mathrm{k}$ & 94 & 26 & 14 & 10 & & & & \\
\hline$|\mathrm{k}-\mathrm{m}|$ & 84 & 12 & 12 & 84 & & & & \\
\hline
\end{tabular}

Further, many more such intriguing patterns are embedded in the domain of Metallic Means.

For illustration, consider following couple of examples, based upon the formula $\frac{\boldsymbol{\delta}_{\mathrm{m}} \times \boldsymbol{\delta}_{\mathrm{n}}+\mathbf{1}}{\boldsymbol{\delta}_{\mathrm{m}}-\boldsymbol{\delta}_{\mathrm{n}}}=\boldsymbol{\delta}_{\mathrm{k}}$

Consider the Triads of Metallic Means formed with $n=6$, and the values of $(\mathbf{m}-\mathbf{n})$, as shown below.

\begin{tabular}{|c|c|c|c|c|c|c|c|c|}
\hline$n$ & 6 & 6 & 6 & 6 & 6 & 6 & 6 & 6 \\
\hline$m$ & 7 & 8 & 10 & 11 & 14 & 16 & 26 & 46 \\
\hline$m-n$ & 1 & 2 & 4 & 5 & 8 & 10 & 20 & 40 \\
\hline
\end{tabular}

Note the bottom row in above table which contains the values of $(\mathbf{m}-\mathbf{n})$.

The numbers in this (m-n) row exhibit typical $1: 2: 4: 5: 8: 10 \times(1: 2: 4)$ pattern, and remarkably the numbers 3,6 and 9 are conspicuous by their absence from this row !

For Even $\mathrm{n}_{\mathrm{s}}:$ the $(\mathrm{m}-\mathrm{n})$ values exhibit typical $1: 2: 4: 5: 8: 10 \times(1: 2: 4)$ pattern.

For Odd $n_{s}$ : the pattern based upon product of the Prime Factors of $\left(n^{2}+4\right)$ is observed.

In either case, the integers 3, 6 and 9 are conspicuous by their absence from these $(m-n)$ or $(k-n)$ values.

But, what's about integer 7 ? Consider another example with $n=34$, as shown below. 


\begin{tabular}{|c|c|c|c|c|c|c|c|c|c|c|c|c|c|c|c|c|}
\hline $\mathbf{n}$ & 34 & 34 & 34 & 34 & 34 & 34 & 34 & 34 & 34 & 34 & 34 & 34 & 34 & 34 & 34 & 34 \\
\hline $\mathrm{m}$ & 35 & 36 & 38 & 39 & 42 & 44 & 54 & 63 & 74 & 92 & 150 & 179 & 266 & 324 & 614 & 1194 \\
\hline $\mathrm{m}-\mathrm{n}$ & 1 & 2 & 4 & 5 & 8 & 10 & 20 & 29 & 40 & 58 & 116 & 145 & 232 & 290 & 580 & 1160 \\
\hline
\end{tabular}

As any $\mathrm{n}^{\text {th }}$ Metallic Mean $\boldsymbol{\delta}_{\mathrm{n}}$ can give the precise values of other Metallic Means $\boldsymbol{\delta}_{\mathrm{m}}$ and $\boldsymbol{\delta}_{\mathrm{k}}$ by the formula:

$$
\frac{\boldsymbol{\delta}_{\mathrm{m}} \times \boldsymbol{\delta}_{\mathrm{n}}+\mathbf{1}}{\boldsymbol{\delta}_{\mathrm{m}}-\boldsymbol{\delta}_{\mathrm{n}}}=\boldsymbol{\delta}_{\mathbf{k}} ; \text { with } \mathbf{k}_{\max }=\mathbf{m}_{\max }=\mathrm{n}^{2}+\mathrm{n}+4 ;
$$

Hence, $(m-n)_{\max }=\left(\mathbf{n}^{\mathbf{2}}+\mathbf{4}\right)$ which is the all important Radical in the fractional expression of $\mathrm{n}^{\text {th }}$ Metallic Mean $\boldsymbol{\delta}_{\mathrm{n}}$ In above table with $\mathrm{n}=34,(\mathrm{~m}-\mathrm{n})_{\max }=1160$

Consider the Prime Factorization of this (m-n) $\max : 1160=1 \times 2 \times 2 \times 2 \times 5 \times 29$

Note the bottom row $(m-n)$ in above table with $n=34$, the numbers in the $(m-n)$ row exhibit the characteristic pattern based upon these factors $1,2,5$ and 29. Numbers in this $(m-n)$ row are the $1: 2: 4: 5: 8: 10 \times(1: 2: 4)$ multiples of the prime factors $1,2,5$ and 29.

Noticeably, the integer $\mathbf{7}$ is present not directly as (m-n), but it's present only as the Digital Roots of certain (m-n) values; for instance the red shaded number 232 in above example. Such presence of $\mathbf{7}$ as Digital Root of (m-n) values is observed with $n=8,10,11,14,16,22,26,29,34,36,39$, and so on. Remarkably, with $n=26$, 36,39 , etc. multiple $(m-n)$ values are found to have their digital root Seven.

However, the integers 3, 6 and $\mathbf{9}$ are invariably missing from this pattern, they are neither present directly as $(m-n)$, nor as the digital root of any $(m-n)$ or $(k-n)$ values.

The more remarkable aspect of Integer $\mathbf{7}$ in the realm of Metallic Ratios can be observed in the Triads of Metallic Means with $\mathbf{n}=\mathbf{7}$ and Multiples of $\mathbf{7}$.

If $\mathbf{n}=\mathbf{7}, \mathbf{1 4}$, etc. : the values of $\frac{\mathbf{k}}{\mathbf{n}}$ and $\frac{\mathbf{k}+\mathbf{m}}{\mathbf{n}}$ exhibit a very characteristic pattern.

For instance, consider the Triad $\left[\boldsymbol{\delta}_{7}, \boldsymbol{\delta}_{8}, \boldsymbol{\delta}_{60}\right]$

$\frac{\mathbf{k}}{\mathbf{n}}=\frac{\mathbf{6 0}}{\mathbf{7}}=8.571428571428571428571428571428 \ldots \ldots$

$\frac{\mathbf{k}+\mathbf{m}}{\mathbf{n}}=\frac{\mathbf{6 0}+\mathbf{8}}{\mathbf{7}}=9.71428571428571428571428571428 \ldots \ldots$

Note the Digits in Decimal Places: Numbers 3, 6 and 9 are conspicuous by their absence from the Repeating Pattern of $\mathbf{5 7 1 4 2 8}$. 
Exactly similar pattern is observed in all Triads with $\mathbf{n}=\mathbf{1 4}$ :

like $\left[\boldsymbol{\delta}_{14}, \boldsymbol{\delta}_{15}, \boldsymbol{\delta}_{214}\right]$; [ $\left.\boldsymbol{\delta}_{14}, \boldsymbol{\delta}_{16}, \boldsymbol{\delta}_{114}\right]$; [ $\left.\boldsymbol{\delta}_{14}, \boldsymbol{\delta}_{18}, \boldsymbol{\delta}_{64}\right]$; [ $\left.\boldsymbol{\delta}_{14}, \boldsymbol{\delta}_{19}, \boldsymbol{\delta}_{54}\right]$; [ $\left.\boldsymbol{\delta}_{14}, \boldsymbol{\delta}_{24}, \boldsymbol{\delta}_{34}\right]$; etc.

Consider the Triad $\left[\boldsymbol{\delta}_{14}, \boldsymbol{\delta}_{16}, \boldsymbol{\delta}_{114}\right]$

$\frac{\mathbf{1 1 4}}{\mathbf{1 4}}=8.1428571428571428571428571428571428 \ldots \ldots$

$\frac{114+16}{14}=9.28571428571428571428571428571428 \ldots \ldots$

And, exactly same are patterns in the Triads with $\mathbf{n}=\mathbf{2 8}, \mathbf{3 5}, \mathbf{5 6}$, etc. among other multiples of Seven; but NOT with $\mathbf{n}=\mathbf{2 1}, \mathbf{4 2}$, etc. where Digital Root of $\mathbf{n}$ is multiple of Three.

Moreover, consider the Triads of Metallic Ratios with $\mathbf{n}=\mathbf{3}$ or $\mathbf{6}$ :

For instance the Triad $\left[\boldsymbol{\delta}_{3}, \boldsymbol{\delta}_{4}, \boldsymbol{\delta}_{16}\right]$ with $\mathbf{n}=\mathbf{3}$

$\frac{\mathbf{k}}{\mathbf{n}}=\frac{\mathbf{1 6}}{\mathbf{3}}=5.3333333333333333333333333333333 \ldots \ldots \ldots$

$\frac{\mathbf{k}+\mathbf{m}}{\mathbf{n}}=\frac{\mathbf{1 6}+\mathbf{4}}{\mathbf{3}}=6.666666666666666666666666666666 \ldots \ldots$

Note the $\mathbf{3 s}$ and $\mathbf{6 s}$ in the Decimal places.

Similarly, the Triads with $\mathbf{n}=\mathbf{6}$, like $\left[\boldsymbol{\delta}_{6}, \boldsymbol{\delta}_{11}, \boldsymbol{\delta}_{14}\right]$; $\left[\boldsymbol{\delta}_{6}, \boldsymbol{\delta}_{10}, \boldsymbol{\delta}_{16}\right]$; $\left[\boldsymbol{\delta}_{6}, \boldsymbol{\delta}_{8}, \boldsymbol{\delta}_{26}\right]$; [ $\left.\boldsymbol{\delta}_{6}, \boldsymbol{\delta}_{7}, \boldsymbol{\delta}_{46}\right]$; etc.

$\frac{\mathbf{k}}{\mathbf{n}}=\frac{\mathbf{1 4}}{\mathbf{6}}=2.3333333333333333333333333333333 \ldots \ldots$

$\frac{\mathbf{k}+\mathbf{m}}{\mathbf{n}}=\frac{\mathbf{1 4}+\mathbf{1 1}}{\mathbf{6}}=4.166666666666666666666666666666 \ldots \ldots$

Further, the Triads of Metallic Ratios with $\mathbf{n}=\mathbf{9}$ and the multiples of nine $\mathbf{9}$ exhibit their own characteristic patterns.

The point is that the Numbers $\mathbf{3 ,} 6$ and $\mathbf{9}$ exhibit their very peculiar and distinctive attributes, in the dominion of Metallic Numbers. 
Moreover, the idiosyncracy of 3, 6 and 9 is exhibited in several other such patterns of Metallic Means and their Triads.

For instance, if $n$ is multiple of 3 : the digital roots of $[(m-n)+(k-n)]$ are invariably $4,5,4,5 \ldots \ldots$.

And, if $\mathrm{n}$ is NOT multiple of 3 : the digital roots of $[(m-n)+(k-n)]$ are invariably $\mathbf{3}, \mathbf{6}$, or $\mathbf{9}$, as shown below.

For example,

consider $\mathrm{n}=30$ (digital root of $\mathrm{n}$ is 3 )

\begin{tabular}{|c|c|c|c|c|c|c|c|c|}
\hline $\mathbf{n}$ & 30 & 30 & 30 & 30 & 30 & 30 & 30 & 30 \\
\hline $\mathbf{m}$ & 31 & 32 & 34 & 38 & 143 & 256 & 482 & 934 \\
\hline $\mathbf{k}$ & 934 & 482 & 256 & 143 & 38 & 34 & 32 & 31 \\
\hline $\mathbf{m}-\mathbf{n}$ & 1 & 2 & 4 & 8 & 113 & 226 & 452 & 904 \\
\hline $\mathbf{k}-\mathbf{n}$ & 904 & 452 & 226 & 113 & 8 & 4 & 2 & 1 \\
\hline Digital Root of (m-n)+(k-n) & $\mathbf{5}$ & $\mathbf{4}$ & $\mathbf{5}$ & $\mathbf{4}$ & $\mathbf{4}$ & $\mathbf{5}$ & $\mathbf{4}$ & $\mathbf{5}$ \\
\hline
\end{tabular}

Likewise, consider $\mathrm{n}=29$ (digital root of $\mathrm{n}$ is other than 3,6 or 9 )

\begin{tabular}{|c|c|c|c|c|c|c|}
\hline $\mathbf{n}$ & 29 & 29 & 29 & 29 & 29 & 29 \\
\hline $\mathbf{m}$ & 30 & 34 & 42 & 94 & 198 & 874 \\
\hline $\mathbf{k}$ & 874 & 198 & 94 & 42 & 34 & 30 \\
\hline $\mathbf{m}-\mathbf{n}$ & 1 & 5 & 13 & 65 & 169 & 845 \\
\hline $\mathbf{k}-\mathbf{n}$ & 845 & 169 & 65 & 13 & 5 & 1 \\
\hline Digital Root of (m-n)+(k-n) & $\mathbf{9}$ & $\mathbf{3}$ & $\mathbf{6}$ & $\mathbf{6}$ & $\mathbf{3}$ & $\mathbf{9}$ \\
\hline
\end{tabular}


On the last note, it is worth mentioning here that several other intriguing properties of Metallic Ratios and these TRIADS of Metallic Means are described in details in the works mentioned in the References. For instance, these TRIADS are found to be closely associated with Pythagorean Triples and Pythagorean Primes [1][11]; the geometric substantiation of Metallic Ratios and their TRIADS [1] [6] [7] [8] [9] [10]; and close association of Metallic Means with the Pascal's Triangle [12]. Further, all imperical formulae those provide the precise relations between different Metallic Means are described in the work mentioned in Reference [2].

\section{Conclusion:}

This paper illustrated certain intriguing patterns in the realm of Metallic Means, and the special attributes of Numbers 3, 6 and 9 therein. These integers 3, 6 and 9 are conspicuous by their peculiar numerical properties, particularly exhibited in the domain of Metallic Ratios.

\section{References:}

[1] Rajput, Chetansing (2021). "Metallic Means : Beyond the Golden Ratio, New Mathematics and Geometry of all Metallic Ratios based upon Right Triangles, The Formation of the Triples of Metallic Means, And their Classical Correspondence with Pythagorean Triples and $p \equiv 1(\bmod 4)$ Primes, Also the Correlation between Metallic Numbers and the Digits 36 9", JOURNAL OF ADVANCES IN MATHEMATICS, 20, 250-266. https://doi.org/10.24297/jam.v20i.9056

[2] Rajput, Chetansing (2021). Metallic Ratios : Beyond the Golden Ratio; The Mathematical Relationships between different Metallic Means. JOURNAL OF ADVANCES IN MATHEMATICS, 20, 158-166. https://doi.org/10.24297/jam.v20i.9023

[3] Vera W. de Spinadel (1999). The Family of Metallic Means, Vismath 1(3) from Mathematical Institute of Serbian Academy of Sciences and Arts.

[4] Weisstein, Eric W. "Table of Silver means". MathWorld.

[5] "An Introduction to Continued Fractions: The Silver Means", maths.surrey.ac.uk.

[6] Rajput, Chetansing (2021). "A Right Angled Triangle for each Metallic Mean". Journal of Advances in Mathematics. 20: 32-33. https://en.wikipedia.org/wiki/Metallic mean\#cite note-15

[7] Rajput, Chetansing (2021). Golden Ratio. JOURNAL OF ADVANCES IN MATHEMATICS, 20, $19-42$. https://doi.org/10.24297/jam.v20i.8945

[8] Rajput, Chetansing (2021). Metallic Means and Right Triangles: The Geometric Substantiation of all Metallic Ratios JOURNAL OF ADVANCES IN MATHEMATICS, 20, 167-173. https://doi.org/10.24297/jam.v20i.9029

[9] Rajput, Chetansing (2021). Golden Ratio and other Metallic Means: The Geometric Substantiation of all Metallic Ratios with Right Triangles. JOURNAL OF ADVANCES IN MATHEMATICS, 20, 174-187. https://doi.org/10.24297/jam.v20i.9034

[10] Rajput, Chetansing (2021). Metallic Ratio Triads, The Mathematical and Geometric Relations between different Metallic Means, Metallic Numbers and the Right Angled Triangles. JOURNAL OF ADVANCES IN MATHEMATICS, 20, 167-173. https://doi.org/10.24297/jam.v20i.9077

[11] Rajput, Chetansing (2021). Metallic Ratios, Pythagorean Triples \& Pythagorean Primes: New Mathematics and Geometry of Metallic Means, Metallic Numbers, Right Triangles and the Pythagoras Theorem. JOURNAL OF ADVANCES IN MATHEMATICS, 20, 167-173. https://doi.org/10.24297/jam.v20i.9075

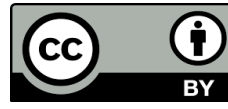


[12] Rajput, Chetansing (2021). Metallic Ratios and Pascal's Triangle : Triads of Metallic Means in the Pascal's Triangle. JOURNAL OF ADVANCES IN MATHEMATICS, 20, 167-173. https://doi.org/10.24297/jam.v20i.9078

[13] Sloane, N. J. A. Sequences A000045/M0692, A000204/M2341 in "The On-Line Encyclopedia of Integer Sequences." https://oeis.org/A000045 and https://oeis.org/A000204

[14] Sloane, N. J. A. Sequences A000129/M1413, A002203/M0360, in "The On-Line Encyclopedia of Integer Sequences." http://oeis.org/A000129 and http://oeis.org/A002203

\begin{tabular}{|ll|l|}
\hline \multicolumn{2}{|c|}{ Select Lecture Videos of Author: } & Contacts: \\
1) & https://youtu.be/vBFVDaFnA2k & Website: https://goldenratiorajput.com/ \\
2) & https://youtu.be/74uF4sBqYjs & Email: chetansingkrajput@gmail.com \\
3) & https://youtu.be/raosniXwRhw & Email: chetansingkrajput1129@gmail.com \\
4) & https://youtu.be/Qh2B1tMl8Bk & Contacts: (+91) 7057521129 \\
\hline
\end{tabular}

